\title{
The prevalence and determinants of female serodiscordance among HIV positive pregnant women attending PMTCT clinic in Owerri, Imo state, Nigeria
}

\section{Innocent O. Eze ${ }^{1}$, Chijioke Okeudo ${ }^{2 *}$, Bamidele U. Ezem², Clara U. Ukoh ${ }^{3}$, Emily A. Nzeribe ${ }^{1}$, Uchenna Nwagha ${ }^{4}$, Tobechi Njoku', Onyeka Uzoma ${ }^{2}$, Onyebuchi A. Duke ${ }^{1}$}

\author{
${ }^{1}$ Department of Obstetrics and Gynecology, Federal Medical Centre, Owerri, Imo State, Nigeria \\ ${ }^{2}$ Department of Obstetrics and Gynecology, Imo State University Teaching Hospital, Orlu, Imo State, Nigeria \\ ${ }^{3}$ Department of Clinical Psychology, Renaissance University Enugu, Enugu State, Nigeria \\ ${ }^{4}$ Department of Obstetrics and Gynaecology, University of Nigeria Teaching Hospital, Enugu, Enugu State, Nigeria
}

Received: 15 February 2018

Accepted: 09 March 2018

\section{*Correspondence:}

Dr. Chijioke Okeudo,

E-mail: cjokeudo@gmail.com

Copyright: (c) the author(s), publisher and licensee Medip Academy. This is an open-access article distributed under the terms of the Creative Commons Attribution Non-Commercial License, which permits unrestricted non-commercial use, distribution, and reproduction in any medium, provided the original work is properly cited.

\begin{abstract}
Background: Human Immunodeficiency Virus sero-discordance is high among heterosexual couples in Africa. However, only few studies have explored the factors that are associated with the prevalence in sub-Saharan Africa. The aim of this study was to determine the prevalence of female sero-discordance among HIV positive pregnant women in Owerri and to assess its possible associated factors.

Methods: A cross sectional study of pregnant women (and their partners) who tested positive to HIV I and II at the Prevention of Mother to Child Transmission (PMTCT) clinic from December 2015 to May 2016 in Federal Medical Center Owerri, Imo state, Nigeria.

Results: A total of 106 HIV positive pregnant women (and their partners) were studied. The prevalence of female serodiscordance was $63.2 \%$ (67/106). Pre-marital serodiscordance contributed about 52.2\% (35/67) female serodiscordance among couples in the study. Sero-discordance rate for the lower, middle, and upper classes were $50 \%$ (28/56), 76.1\% (35/46) and 100\% (4/4) respectively and was statistically significant $(\mathrm{p}<0.01)$. Condom use was significantly associated with female serodiscondance $(\mathrm{P}<0.01)$. CD4+ count of the female partner at booking was also found statistically significantly associated with female serodiscordance $(\mathrm{P}<0.01)$.

Conclusions: There is high prevalence of female serodiscordance among HIV positive pregnant women in Owerri. Pre-marital serodiscordance contributed significantly to high level of female serodiscordance among couples. Higher social class, condom use and high female- partner CD4+ count are significantly associated with female serodiscordance.
\end{abstract}

Keywords: HIV, Pregnant women, Sero-discordant

\section{INTRODUCTION}

Human Immunodeficiency Virus and Acquired Immunodeficiency Syndrome (HIV/ AIDS) pandemic has remained one of the most challenging health/ social issues in recent few decades. According to 2014 National
HIV Sero-prevalence Sentinel Survey among Pregnant Women Attending Antenatal Clinics in Nigeria the prevalence of HIV was $3.0 \%{ }^{1}$

In Africa, more than $85 \%$ of adult HIV infections are due to heterosexual transmission. ${ }^{2}$ In response to growing 
evidence that married or cohabitating sero-discordant couples are important source of new HIV infections in sub-Saharan Africa, programs are being urged to target prevention efforts to married or cohabitating serodiscordant couples. ${ }^{2,3}$ HIV sero-negative partners in discordant cohabiting couples (one partner is HIV positive and the other negative) are at a $10 \%$ (or more) annual risk of acquiring HIV infection. ${ }^{3}$ Hence, seronegative partners in discordant cohabiting relationships are substantially exposed to risk of acquiring HIV.

Nevertheless, what continues to baffle many including medical personnel is the increasing incidence/prevalence of discordant relationship. Some studies especially in Africa have shown that female sero-discordance (where the female partner is positive and male negative) is more prevalent than male sero-discordance (where the male partner is positive and female negative). ${ }^{4-8}$ Researchers are yet to come up with an explanation for this situation, although a couple of indicators have been observed for this occurrence. ${ }^{9-13}$ Analysis of HIV data in five African countries (Burkina Faso, Ghana, Cameroon, Kenya and Tanzania) showed that extra-marital sexual activity among co-habiting women was a substantial source of vulnerability to HIV infection. ${ }^{13}$ This was at odds with levels of self-reported marital infidelity by females and with the common perception that unfaithful male are the main link between high risk group and the general population. $^{13}$ According to Sagay et al, socio demographic factors including regional, ethnic and religious settings play significant role in the dynamics of HIV transmission among couples in Nigeria. ${ }^{5}$

Some studies have suggested that male-to-female transmission of HIV is higher than female-to-male transmission. ${ }^{14,15}$ The possible causes have been traced to the interrelation of the several factors ranging from transmission rate due to anatomical structure of male and female genitals where men are less vulnerable to contracting the virus than women. ${ }^{15}$ However, other studies especially in African settings have reported a very similar transmission rate between the sexes. ${ }^{10}$

Apart from few prevalence studies (non-in FMC Owerri) on female HIV sero-discordance in the South Eastern Nigeria, authors did not come across any studies that assessed the possible socio-demographic and behavioral factors that may be significantly associated with female sero-discordance. This study, therefore, was undertaken to determine the prevalence of female sero-discordance and assess the possible socio-demographic and behavioral factors that may be significantly associated with female sero-discordance among HIV positive pregnant women attending PMTCT clinic in Federal Medical Center Owerri, Imo state Nigeria.

\section{METHODS}

This was a cross sectional study carried out from December 2015 to May 2016 on consecutively recruited pregnant women (with their partners) who tested positive to HIV I and II at the PMTCT clinic Federal medical Centre (FMC) Owerri.

FMC is a tertiary health institution situated in Owerri South East zone of the country and the capital city of Imo State., The population was predominantly Igbos and Christians. Federal Medical Center Owerri serves mainly Imo, parts of Anambra, Enugu, Abia, and Rivers states. The FMC Owerri has an established Obstetrics and Gynecology department with four firms. One of the four firms oversee the PMTCT program supported by Center for Clinical Care and Clinical Research of Nigeria (CCCRN) project. The study was approved by the research and ethical committee of FMC Owerri. Informed written consents were obtained from the subjects.

Data were collected using a structured self-administered and validated questionnaire with the assistance of the midwives who were trained in voluntary counseling and testing (VCT). The laboratory investigations were done at the Center for Clinical Care and Clinical Research of Nigeria (CCCRN) laboratory in FMC Owerri. Screening for HIV I and II was carried out by laboratory staff with serial algorithm using Determine and Stat-pak (and Unigold as tie-breaker where necessary).

Those included in the study were guided to fill out questionnaire on bio data, duration of marriage/ cohabitation, retroviral status before marriage/ cohabitation, sexual behavior (frequency, condom/ other barrier use). The participants' male partners also presented to the clinic to provide information bordering on their (male partner) sexual behaviors. To ensure individual partner's confidentiality in sensitive information, each partner was interviewed separately. Social classes were assigned to the women using partner's occupation and educational status of the women according to the scoring system designed by Olusanya et al. for Nigeria and other African countries. ${ }^{16}$ The CD4+ Count of the female partner at booking was determined from the laboratory using a power-operated qualitycontrolled Cy Flow Counter 1 (made in Germany). The use of/ and duration on HAART by the female partner was also determined for those already on HAART.

\section{Statistical analysis}

Data were computed and analyzed using computer software package for social sciences version 20 (SPSS, Inc. USA). Descriptive statistics (mean, standard deviation, percentages etc.) was determined for continuous variables. Pearson Chi square tests, a nonparametric inferential statistic were used to determine significant association for dichotomous variables. Multiple logistic regression analysis was used to identify the factors that were independently associated with female sero-discordance. P-values $<0.05$ at $95 \%$ confidence interval were considered statistically significant. 


\section{RESULTS}

A total of $106 \mathrm{HIV}$ positive pregnant women were studied. The mean age was $31.5 \pm 4.1$ years with a range of 21-42 years. The mean years of cohabitation were $5.1 \pm 3.4$ years with a range of $1-15$ years. Average sexual frequency per week among couples ranges from 1-5 with a mean of $1.67 \pm 1.3$. The mean parity was $2.0 \pm 1.5$ with a range of $0-7$.

Sixty-seven (67) of these women had sero-negative male partners, while 39 had sero-positive male partners, giving a female sero-discordance prevalence of $63.2 \%$ and concordance rate of $36.8 \%$. Of the study population $52.8 \%(56 / 106)$ was lower class, middle class $43.4 \%$ $(46 / 106)$ and upper class $3.8 \%(4 / 106 ;)$ of the HIV positive pregnant women. Majority of the women (97/106; 91.5\%) knew their HIV statuses before marriage/cohabitation. Out of these, fifty-six $(56 / 106$; $52.8 \%)$ were seropositive for HIV while $(41 / 106 ; 38.7 \%)$ were negative before marriage. Nine $(9 / 106 ; 8.5 \%)$ did not know their status before marriage/cohabitation. Majority (101/106; 95.5\%) of the male partners were also aware of their HIV statuses before marriage/cohabitation. Twenty-one $(21 / 106 ; 19.8 \%)$ were positive before marriage while $(80 / 106 ; 75.5 \%)$ were negative. Five $(5 / 106 ; 4.7 \%)$ did not know their statuses before marriage. However, only 1 out of the 5 who did not know their statuses before marriage was positive at the time of study. Since HIV positive persons remain so for life, it follows that the remaining 4 were negative before marriage (Table 1).

Table 1: Participants' characteristics.

\begin{tabular}{|lcl|}
\hline & \multicolumn{2}{c|}{ Frequency $(\%)$} \\
\hline Variable & Female & Male \\
\hline $20-24$ & $7(6.6)$ & $0(0.0)$ \\
\hline $25-29$ & $24(22.6)$ & $11(10.4)$ \\
\hline $30-34$ & $48(45.3)$ & $22(20.8)$ \\
\hline $35-39$ & $25(23.6)$ & $53(50.0)$ \\
\hline$\geq 40$ & $2(1.9)$ & $20(18.9)$ \\
\hline Total & $106(100.0)$ & $106(100.0)$ \\
\hline Education & & \\
\hline Primary & $5(4.7)$ & $1(0.9)$ \\
\hline Secondary & $65(61.3)$ & $73(69.0)$ \\
\hline Tertiary & $36(34.0)$ & $32(30.1)$ \\
\hline Social class & & \\
\hline Lower & $56(52.8$ & \\
\hline Middle & $46(43.4)$ & \\
\hline Upper & $4(3.8)$ & \\
\hline HIV status before marriage & \\
\hline Positive & $56(52.8)$ & $21(19.8)$ \\
\hline Negative & $41(38.7)$ & $80(75.5)$ \\
\hline Unknown & $9(8.5)$ & $5(4.7)$ \\
\hline HIV status at the time of study & \\
\hline Positive & $106(100)$ & $39(36.8)$ \\
\hline Negative & $0(0.0)$ & $67(63.2)$ \\
\hline
\end{tabular}

Female sero-discordance rate for the lower, middle, and upper classes were $(28 / 56 ; 50 \%),(35 / 46 ; 76.1 \%)$ and $(4 / 4 ; 100 \%)$ respectively and was statistically significant $(\mathrm{P}<0.01)$. There were no significant relationships between age, parity, duration of marriage/cohabitation, average sexual frequency per week and female sero-discordance (Table 2).

Table 2: Association of variables with female serodiscordance.

\begin{tabular}{|c|c|c|c|}
\hline Variable & $\begin{array}{l}\text { Discordant } \\
\text { female }(\%)\end{array}$ & P-value & $\begin{array}{l}\text { Crude OR } \\
(95 \% \text { CI) }\end{array}$ \\
\hline \multicolumn{4}{|l|}{ Age } \\
\hline$\leq 34$ & $57 / 85(67.1)$ & \multirow{2}{*}{0.140} & \\
\hline$\geq 35$ & $10 / 21(47.6)$ & & \\
\hline \multicolumn{4}{|l|}{ Parity } \\
\hline 0 & $28 / 38(73.7)$ & \multirow{3}{*}{0.429} & \\
\hline $1-5$ & $38 / 66(57.6)$ & & \\
\hline$>5$ & $1 / 2(50.0)$ & & \\
\hline \multicolumn{4}{|c|}{ Social class } \\
\hline Lower & $28 / 56(50.0)$ & \multirow{3}{*}{$<0.01$} & $(0.041-2.200)$ \\
\hline Middle & $35 / 46(76.1)$ & & (ref) \\
\hline Upper & $4 / 4(100$ & & $(0.041-2.200)$ \\
\hline
\end{tabular}

Only $(17 / 84 ; 20.2 \%)$ of the 84 male partners that were sero-negative before marriage were infected or seroconverted after marriage, while 41 of the female seroconverted after marriage/cohabitation. Pre-exposure and/or post-exposure prophylaxes were very uncommon. Only $2(1.9 \%)$ practices it among the participants. Condom use was significantly associated with female sero-discondance $(\mathrm{P}=0.002)$. Female sero-discordance rate was $62.7 \%$ among couple that used condom (usage ranging from "occasionally" to "always except for conception") for intercourse and 37.3\% among those that never used condom (Figure 1).

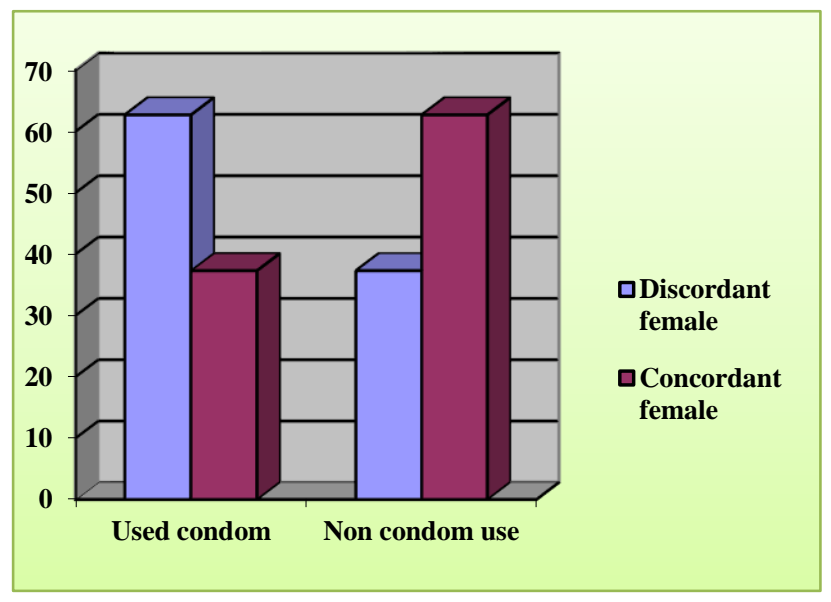

Figure 1: Condom use and female sero-discordance.

Out of the 17 male partners that seroconverted after marriage/cohabitation, $12(70.6 \%)$ were of couple that never used condom for intercourse while only 5 (29.4\%) used condom. 
Majority $(86 ; 81 \%)$ of the female participants were on HAART at booking and no statistically significant relationship was found between use of HAART and female sero-discordance $(\mathrm{p}=0.12)$. Duration of use of HAART was also not found statistically significant $(\mathrm{p}=0.08)$.

CD4+ count of the female partner at booking was found statistically significantly associated with female serodiscordance $(\mathrm{P}=0.009)$. Female sero-discordance rate was $26.9 \%$ among couples whose female partners CD4+ was less than $200 / \mathrm{uL}$ and $73.1 \%$ among couple with female CD4+ count of 200/uL and above (Figure 2).

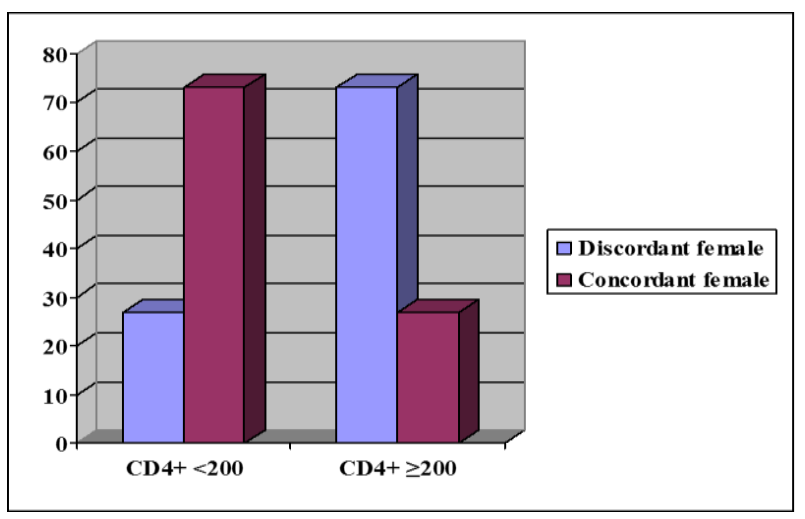

Figure 2: Female CD4+ count and female serodiscordance.

Binary Logistic regression between partners status, CD4+ count and non -use of condom showed that partners of females with CD4+ $<200 / \mathrm{uL}$ had about 5.5 times higher odds of seroconversion than those with CD4+ of 200/uL and above (crude odds ratio $(\mathrm{OR})=5.505$, CI 1.36522.203: $\mathrm{P}=0.02)$. Male partners in couples who never used condom for intercourse had about 4.3 times higher odds of seroconversion than those who used condom (crude odds ratio $(\mathrm{OR})=4.276$, CI 1.818-10.058: $\mathrm{P}=0.001)$. Multiple logistic regression between partners' status, CD4+ count of the female and non -use of condom strongly suggests both were independent risk factors for sero-conversion of HIV negative partners.

\section{DISCUSSION}

The finding of $63.2 \%$ female discordance rate in this study is close to the rate of $54.7 \%$ found in Nnewi (south east Nigeria) but much lower than $89 \%$ found in Cross River (south-south Nigeria), and $78.8 \%$ found in Benin city (south west Nigeria) ${ }^{5-7}$ However, it is higher than the rate of $7.7 \%$ and $48.4 \%$ found in Kano and Jos respectively, all in Northern Nigeria. ${ }^{5}$ This finding fits into the earlier survey by Sagay et al. which revealed a significant difference in female sero-discordance across sociocultural and geopolitical zones in Nigeria in which it showed a higher female sero-discordance rate in the Southern than Northern Nigeria. ${ }^{5}$ Compared to other studies from Africa, present finding is much higher than the population-based estimate of sero-discordance of $2 \%$ and $13 \%$ found in Rwanda and Zimbabwe and Lesotho respectively. ${ }^{10}$ This difference in the finding could be due to varying HIV prevalence across the zones or a reflection of mixed epidemic reported in some studies. ${ }^{14}$ It is also possible such differences could be due to varying cultural practices, literacy and socioeconomic levels across the geopolitical zones and countries.

The finding of higher percentage $(38.7 \%)$ of infection or seroconvertion after marriage/cohabitation among female partners compared to $21.3 \%$ among male partners may be explained by the hypothesis that women are more at risk to HIV infection (in heterosexual intercourse) than men. It is in tandem with several surveys especially in Africa that have shown a higher risk of infection in women compared to men. ${ }^{4-8}$ The possible causes have been traced to the interrelation of the several factors including differences in anatomical structure of male and female genitals that make men less vulnerable to contracting the virus than women. ${ }^{15}$ However, the study could not ascertain whether the HIV infection after marriage in both sexes was due to intra- or extra-marital sexual relationship or other negligible risk factors. To establish that will require a well-controlled prospective study, if ethically permissible.

Majority of the participants had pre-marital/cohabitation knowledge of their HIV status. This is a common practice these days. It can be deduced from Table 1 that about 35 HIV positive women got married to HIV negative partners. It is possible that couples don't know the implication of their partner's positive status before marriage and/ or intentionally go into marriage/ cohabitation with sero-discordant partners or at worst the sero-positive partner did not disclose their real status to their partner before marriage. Either of these will pose a great problem in the successful prevention of HIV infection. In this study, lower class was $52.8 \%$, middle class $43.4 \%$, and upper class $3.8 \%$ of the HIV positive pregnant women. This may imply that HIV infection was more prevalent among women of lower and middle class compared to the upper class in Owerri. It could also be that, for socioeconomic reasons, the upper class was less likely to access health care in a public health facility than the middle and lower classes. Sero-discordance rate for the lower, middle, and upper classes were 50\%, 76.1\% and $100 \%$ respectively, and were statistically significant. This may be explained by the assumption (if most couple had discordant female partners at onset) that serodiscordant couples of higher social class were more likely to be aware and adhere to measures for prevention of transmission to the seronegative partners than those of the lower and middle classes and hence more likely to remain sero-discordant than the later. It could also be that discordant marriages were commoner among the upper than the middle and lower classes. However, the very small population of the upper class in the study is a limitation that requires caution in interpretation of findings. 
There were no significant relationships between age, parity, duration of marriage/cohabitation, sexual frequency and female sero-discordance. All things being equal, increased exposure (occasioned by longer duration of marriage/cohabitation and higher sexual frequency) should be associated with increased risk of infection ${ }^{11}$ ${ }^{13}$ and affect the discordance rate. However, other covariables like CD4+ count, use of HAART and sexual practice (condom use etc.) can confound the effect of increased exposure.

Condom use was significantly associated with female sero-discondance. Female sero-discordance rate was $62.7 \%$ among couple that used condom (usage ranging from "occasionally" to "always except for conception") for intercourse compared to $37.3 \%$ among those that never used condom. Although direct causality cannot be established here considering the cross sectional nature of study, and one may argue that sero-discordant couples are more likely to use condom (to protect the uninfected partner) than sero-concordant couples who may feel have no need for protection, this finding supports the fact that correct and consistent use of condom is protective against HIV infection. ${ }^{17,18} \mathrm{Also}$, it is interesting that when the 17 male partners that seroconverted after marriage/ cohabitation were cross -tabulated with condom use, 12 $(70.6 \%)$ were of couples that never used condom for intercourse compared to only $5(29.4 \%)$ who used condom. This may imply that, all things being equal, condom use may have reduced male sero-conversion rate from $21 \%(17 / 80)$ to $6.3 \%(5 / 80)$ in this study. This finding is tandem with that of Allen et al. where condom use was found to reduce the annual risk of HIV transmission among sero-discordant couple from 20-25\% to $3-7 \%{ }^{17}$ One can assume that even the 5 that seroconverted despite condom use may be due to improper and inconsistent use.

CD4+ count of the female partner at booking was found statistically significantly associated with female serodiscordance. This can be explained by the fact that CD4+ count is a major disease marker in HIV positive patients as it reflects the immune status of the patients (used as AIDS-defining immunological condition when value is less than 200/ul ${ }^{2}$ ). CD4+ count is also known to have inverse relationship with viral load which has been shown as the most powerful predictor for HIV transmission to an uninfected partner. ${ }^{19}$ However, one of the limitations of this study was inability to assess the viral load of the participants. Again, the power of this finding is weakened by the cross-sectional nature of the study as the CD4+ count at booking may not represent the count at the time of infection of the partner, all things being equal.

Use of HAART and duration of use were not found statistically significantly associated with female serodiscordance. However, this can be explained by the fact that majority $(81 \%)$ were already on HAART at booking. It was not ethically permissible to keep some HIV positive pregnant women from HAART for purpose of study considering the already known benefit of HAART to mother, fetus, and partner. The knowledge and practice of pre-exposure prophylaxis were very uncommon $(<2 \%)$ among the discordant participants.

\section{CONCLUSION}

In conclusion, this study has shown a high prevalence of female sero-discordance among HIV positive pregnant women in FMC Owerri. Higher social class, condom use and higher female-partner CD4+ count are significantly associated with female sero-discordance. The knowledge and practice of pre-exposure prophylaxis were very uncommon $(<2 \%)$ among the discordant participants.

\section{Funding: No funding sources}

Conflict of interest: None declared

Ethical approval: The study was approved by the Research and Ethical Committee of FMC Owerri

\section{REFERENCES}

1. Federal Ministry of Health. Fact Sheet: National HIV Sero-prevalence Sentinel Survey among Pregnant Women Attending Antenatal Clinics in Nigeria, 2015. Available http://nigeriahealthwatch.com/wpcontent/uploads/bsk-pdf-manager/1176.

2. Dunkle KL, Stephenson R, Karita E, Chomba E, Kayitenkore K, Vwalika C, et al. New heterosexually transmitted HIV infections in married or cohabiting couples in urban Zambia and Rwanda: an analysis of survey and clinical data. Lancet. 2008;371(9631):2183-91.

3. Hugonnet S, Mosha F, Todd J, Mugeye K, Klokke A, Ndeki L, et al. Incidence of HIV infection in stable sexual partnerships: a retrospective cohort study of 1802 couples in Mwanza Region, Tanzania. J Acquire Immune Defic Syndr. 2002;30:73-80.

4. Hudson CP. The importance of transmission of HIV1 in discordant couples in the population dynamics of HIV-1 infection in rural Africa. Int J STD AIDS. 1996;7:302-6.

5. Sagay AS, Onakewhor J, Galadanci H, Emuveyan EE. HIV status of partners of HIV positive pregnant women in different regions of Nigeria: matters arising. Afr J Med Med Sci. 2006;35Suppl:125-9.

6. Ezeama CO, Eleje GU, Okonkwo T, Ikechebelu JI. Partner human immunodeficiency virus serodiscordance in Nnewi, Nigeria. J HIV Hum Reprod. 2014;2:2-7.

7. Onovo A. Prevalence of sero-discordance among pregnant women attending PMTCT services and their partners in Cross-River State, Ngeria.:6th IAS Conference on HIV Pathogenesis and Treatment: Abstract no. CDC338.

8. Chemaitelly H, Cremin I, Shelton J, Hallett TB, Abu-Raddad LJ. Distinct HIV discordancy patterns by epidemic size in stable sexual partnerships in subSaharan Africa. Sex Transm Infect. 2012;88(1):51-7. 
9. Carpenter LM, Kamali A, Ruberantwari A, Malamba SS, Whitworth JA. Rates of HIV-1 transmission within marriage in rural Uganda in relation to the HIV sero-status of the partners. AIDS. 1999;13(9):1083-9.

10. Lurie MN, Williams BG, Zuma K, MkayaMwamburi D, Garnett GP, Sweat MD, et al. Who infects whom? HIV-1 concordance and discordance among migrant and non-migrant couples in South Africa. AIDS. 2003;17(15):2245-52.

11. Eyawo O, de Walque D, Ford N, Gakii G, Lester RT, Mills EJ. HIV status in discordant couples in subSaharan Africa: a systematic review and metaanalysis. Lancet Infect Dis. 2010;10 (11):770-7.

12. Guthrie BL, de Bruyn G, Farquhar C. HIV-1discordant couples in sub-Saharan Africa: explanations and implications for high rates of discordancy. Curr HIV Res. 2007;5(4):416-29.

13. Damien de Walque (Development Research Group, The World Bank). Discordant couple; HIV infection among couples in Burkina Faso, Ghana, Cameroon, Kenya and Tanzania. 2006.

14. Ujah I, Ezechi O, Aigbe G. HIV status discordance: associated factors among HIV positive pregnant women in Lagos, Southwest Nigeria. Afr J Reprod Health. 2015;19(2):108-16.

15. Gray RH, Wawer MJ, Brookmeyer R, Sewankambo NK, Serwadda D, Wabwire-Mangen F, et al. Probability of HIV-1 transmission per coital act in monogamous, heterosexual, HIV-1-discordant couples in Rakai, Uganda. Lancet. 2001;357(9263):1149-53.

16. Olusanya O, Okpere E, Ezimokhai M. The importance of social class in fertility control in a developing country. West African J Med. 1985;4:205-12.

17. Serwadda D, Gray RH, Wawer MJ, Stallings RY, Sewankambo NK, Konde-Lule Bongs Lainjo JK, et al. The social dynamics of HIV transmission as reflected through discordant couple in Uganda. AIDS. 1995;9(7):745-50.

18. Allen S, Tice J, Van de Perre P, Serufilira A, Hudes E, Nsengumuremyi F, et al. Effect of sero-testing with counselling on condom use and seroconversion among HIV discordant couples in Africa. BMJ. 1992;304(6842):1605-9.

19. Ezeanochie M, Olagbuji B, Ande A, Oboro V. Fertility preferences, condom use, and concerns among HIV-positive women in sero-discordant relationships in the era of antiretroviral therapy. Int $\mathbf{J}$ Gynaecol Obstet. 2009;107(2):97-8.

Cite this article as: Eze IO, Okeudo C, Ezem BU, Ukoh CU, Nzeribe EA, Nwagha U. The prevalence and determinants of female serodiscordance among HIV positive pregnant women attending PMTCT clinic in Owerri, Imo state, Nigeria. Int J Reprod Contracept Obstet Gynecol 2019;8:115-20. 